\title{
RPAS ACCURACY TESTING FOR USING IT IN THE CADASTRE OF REAL ESTATES OF THE CZECH REPUBLIC
}

\author{
E. Housarová ${ }^{a}$, K. Pavelka ${ }^{a}$, J. Šedina $^{\text {a }}$ \\ ${ }^{\text {a }}$ Czech Technical University in Prague, Faculty of Civil Engineering, Department of Geomatics, Thakurova 7, 166 29, Prgue 6, \\ Czech Republic - eliska.housarova@fsv.cvut.cz
}

Commission I, ICWG I/Vb

KEY WORDS: RPAS, cadastre of real estates, GNSS, geodetic measurement, photogrammetry

\begin{abstract}
:
In the last few years, interest in the collection of data using remotely piloted aircraft systems (RPAS) has sharply risen. RPAS technology has a very wide area of use; one of its main advantages is its accuracy, timeliness of data, frequency of collecting data and low operating costs. RPAS can be used for the mapping of small, dangerous and inaccessible areas in contrast with ordinary aerial photogrammetry. In the cadastre of real estates of the Czech Republic, it is possible to map out areas by using aerial photogrammetry, so it has been done in the past. However, this is a relatively expensive and complex technology, and therefore we are looking for new alternatives. An alternative would be to use RPAS technology for data acquisition. The testing of the possibility of using RPAS for the cadastre of real estates of the Czech Republic is the subject of this paper. When evaluating results we compared point coordinates measured by geodetic method, GNSS technology and RPAS technology.
\end{abstract}

\section{INTRODUCTION}

Cadastre of real estates plays an important and irreplaceable role in the lives of people not only in the Czech Republic, but also throughout the world. The information system of the cadastre of real estates contains a wealth of data on the real estates and their owners, which has to be managed quickly, efficiently and in accordance with the law. People's demand for this data is still increasing. Currently, the usability RPAS (Remotely Piloted Aircraft System) is mostly discussed in the field of cadastre of real estates and mapping. It is a modern and useful technology for the contactless mapping and monitoring of small areas. These systems can provide different types of data, e.g. visible spectral range data, infrared data, multispectral and hyperspectral data, even Lidar data. The Czech Republic border region was mostly mapped using aerial photogrammetry, but it is in most cases with a large aircraft with a calibrated, accurate and very expensive camera, which was adapted for these purposes and equipped by an inertial measuring unit. From a different point of view, RPAS are many times smaller and equipped by commercially available cameras. One of the advantages of this technology is its mobile deployment in the field and less dependence on the weather; imaging can take place even when it is cloudy. Orthophoto, which is based on RPAS imaging, is the basis for mapping of small areas to the several km2 (Cramer, 2015; Manyoky et al, 2011; Housarova et al, 2015, Sedina et al, 2015).

\section{MEASUREMENT OF POINTS ACCORDING TO THE INSTRUCTIONS FOR RENEWAL OF CADASTRE DOCUMENTATION AND ITS TRANSFER}

\subsection{Terrestrial measurement methods}

Points of minor geodetic control are measured by (Barešová et al, 2015; ČÚZK, 2015):

1) Survey nets with measured horizontal angles and distances.
2) Traverses oriented on both ends and connected on both ends. Traverses shorter than $1.5 \mathrm{~km}$ can be oriented only on one end or without orientation. Traverses without orientation are able to have a maximum 4 traverse sides and its orientation angle is measured at least from one traverse point. Table 1 shows geometrical parameters and permitted deviations of traverse.

\begin{tabular}{|c|c|c|c|c|}
\hline \multirow{2}{*}{$\begin{array}{l}\text { Connecting } \\
\text { points }[\mathrm{m}]\end{array}$} & \multirow{2}{*}{$\begin{array}{l}\text { Per. dist. } \\
\text { of side } \\
\text { [m] }\end{array}$} & \multirow{2}{*}{$\begin{array}{c}\text { Per. } \\
\text { dist. of } \\
\text { traverse } \\
{[\mathrm{m}]}\end{array}$} & \multicolumn{2}{|c|}{$\begin{array}{l}\text { Permitted traverse } \\
\text { misclosure }\end{array}$} \\
\hline & & & $\begin{array}{l}\text { Angle } \\
\text { [gon] }\end{array}$ & $\begin{array}{l}\text { Dist. } \\
{[\mathrm{m}]}\end{array}$ \\
\hline FHC, NDP & $200-1500$ & 5000 & $2.5 \cdot(\mathrm{n})^{1 / 2}$ & $\begin{array}{l}0.0025 \\
\left(\sum \mathrm{d}\right)^{1 / 2}\end{array}$ \\
\hline FHC, NDP & $50-400$ & 3000 & $5.0 \cdot(\mathrm{n})^{1 / 2}$ & $\begin{array}{l}0.004 \cdot \\
\left(\sum \mathrm{d}\right)^{1 / 2}\end{array}$ \\
\hline $\begin{array}{c}\text { MGC, } \\
\text { FHC, NDP }\end{array}$ & $50-400$ & 1500 & $10 \cdot(\mathrm{n})^{1 / 2}$ & $\begin{array}{l}0.006 \cdot \\
(\Sigma \mathrm{d})^{1 / 2}\end{array}$ \\
\hline
\end{tabular}

Table 1. Parameters and permitted deviations of traverse

Where Per. dist. is permitted distance, FHC is fundamental horizontal control, NDP is net densification point, MGC is minor geodetic control, $\mathrm{n}$ is number of all traverse points and $\Sigma \mathrm{d}$ is sum of length of traverse sides, traverse has a maximum of 15 new points and permitted ratio of neighbouring sides is 1:3.

3) Forward intersection or by intersection from distances or by combined intersection at least from 3 points of fundamental horizontal control, fixed point of minor geodetic control or different points corresponding to the appropriate precision. At the determined point the angle of intersection has to be in the range from 30 to 170 gon and the distance from the fixed point to the determined point mustn't be greater than $1500 \mathrm{~m}$. Directions are measured in two sets in a case that the point distance is greater than $500 \mathrm{~m}$.

4) Oriented distance with orientation at the point to 2 points of fundamental horizontal control, fixed point of minor geodetic control or different points which quadratic mean of standard deviation of $\mathrm{X}$ and $\mathrm{Y}$ is less than $0.04 \mathrm{~m}$ or with orientation at 
the point and at the determined point and to oriented distance to the $1500 \mathrm{~m}$. The condition is that the length of the oriented distance is no longer than the furthermost orientation. If the oriented distance is longer than $800 \mathrm{~m}$, it is measured in two sets. If the oriented distance initial point has mean quadratic standard deviation of $\mathrm{X}$ and $\mathrm{Y}$ between $0.04 \mathrm{~m}$ and $0.06 \mathrm{~m}$, its length must not be longer than $300 \mathrm{~m}$.

5) Oriented distance with orientation at determined point at least to 3 points of fundamental horizontal control, fixed point of minor geodetic control or different points which quadratic mean of standard deviation of $\mathrm{X}$ and $\mathrm{Y}$ is less than $0.04 \mathrm{~m}$. At the determined point the angle of intersection has to be in the range from 30 to 170 gon between direction with measured distance and other directions. Directions are measured in two sets in a case that the point distance is greater than $800 \mathrm{~m}$. If the oriented distance initial point has mean quadratic standard deviation of $\mathrm{X}$ and $\mathrm{Y}$ between $0.04 \mathrm{~m}$ and $0.06 \mathrm{~m}$, its length must not be longer than $300 \mathrm{~m}$.

6) Points on technical objects are measured by traverse, usually to the distance of $50 \mathrm{~m}$ from the auxiliary survey point. Distances between points are measured as a control measurement and has to agree with criteria of permitted deviation.

Horizontal angles are measured at least at one set by theodolite, which direction accuracy is better than 0.0006 gon. If distances are shorter than $500 \mathrm{~m}$, it is possible to use theodolite with accuracy 0.002 gon. Permitted deviation of angular misclosure of one set (repeated measurement of first direction) and permitted difference between sets is 0.003 gon. Distances are measured twice by distance meter with accuracy $0.01 \mathrm{~m}$, on the both sides, if possible, and using surveying prisms on the points. Survey tape can be used for short distances, typically within its length. Calibrated distance meter is used for measuring and measured distances are corrected about physical and mathematical corrections and about reduction to plane projection of S-JTSK. Permitted difference of double measured distances is $0.02 \mathrm{~m}$ for distances shorter than $500 \mathrm{~m}$ and 0.004 $\mathrm{m}$ for distances longer than $500 \mathrm{~m}$. Centering data are not introduced in, if eccentricity is lower than $0.01 \mathrm{~m}$. For traverse and for survey net it is used a set for the three-tripod system for measurement.

\begin{tabular}{|l|c|c|}
\hline \multirow{2}{*}{ Used points } & \multicolumn{2}{c|}{$\begin{array}{c}\text { Permitted } \\
\text { deviation }\end{array}$} \\
\cline { 2 - 3 } & $\begin{array}{c}\text { Angle } \\
\text { [gon] }\end{array}$ & $\begin{array}{c}\text { Distance } \\
{[\mathrm{m}]}\end{array}$ \\
\hline \multirow{2}{*}{ FHC and their OP1 and OP2 } & 0.0015 & 0.03 \\
\hline FHC and NDP & 0.0015 & 0.05 \\
\hline NDP & 0.0020 & 0.05 \\
\hline $\begin{array}{l}\text { Points according to the letter a), b), c) } \\
\text { and OP 3 }\end{array}$ & 0.0030 & 0.05 \\
\hline $\begin{array}{l}\text { Points according to the letter a) and } \\
\text { according to the letter f) }\end{array}$ & 0.0060 & - \\
\hline MGC & 0.0300 & 0.15 \\
\hline $\begin{array}{l}\text { Points according to the letter f) and } \\
\text { points on a technical objects which are } \\
\text { associated to the same determining } \\
\text { point to the distance of 50 m }\end{array}$ & 0.0500 & 0.04 \\
\hline
\end{tabular}

Table 2. Permitted deviations for measurement between horizontal controls

Table 2 shows permitted deviations for measurement between horizontal controls. Differences of horizontal angles and distances between measured and computed from coordinates or initially determined values mustn't exceed permitted deviations.

\subsection{Photogrammetric methods}

Points of minor geodetic control or control points are determined by analytical aerotriangulation or digital aerotriangulation. Aerial survey photos with at least $60 \%$ overlap and $30 \%$ sidelap, taken by calibrated digital aerial camera, are used. It is appropriate that these photos were delivered together with their elements of exterior orientation, measured during a survey flight by apparatuses GNSS/IMU. The initial points are the control points of the fundamental horizontal controls and net densification points, or other points satisfying criteria of permitted deviations. These initial points have to be identifiable in photos and uniformly distributed. Heights above sea level of initial points are determined with a standard deviation to the $0.10 \mathrm{~m}$ (Barešová et al, 2015; ČÚZK, 2015).

\subsection{GNSS technology}

Determination of the position of a point is not permitted from a single measurement, or a single observation, or a single vector when processing subsequently. The required number of measurements is at least two. It has to be independent measurements, either two independent GNSS measurements or one GNSS measurement and one terrestrial measurement. During repeated RTK observation or when measuring vector, control measurements have to be performed at a different constellation of satellites and it is recommended to use a different antenna height. For coordinate transformation to SJTSK, only an approved transformation program is used. An appropriate number of identical points are selected, but at least four, from close area of determined points. The coordinates of these can't have lower accuracy, than is required for determined points. From the selected points it is necessary to select those that are uniformly distributed in the area and so that their number was proportional to area size and any determined point is not distanced out of the connection of the closest identical points to him more than $1 / 10$ of the length of the connection of the closest identical points. If the area is large, it is necessary to divide area into smaller sub-areas and keep overlap for selection of identical points. It is recommended to use the same transformational relationships including mathematical process of transformation, for any surveying works in a given area in order to maintain homogeneity of surveying work. Connection to a geocentric coordinate system, in which the transformational relationships were determined, is carried out by using at least two identical points, (Barešová et al, 2015; ČÚZK, 2015).

\section{USING RPAS FOR CADASTRE OF REAL ESTATES}

RPAS appears to be a suitable alternative of data collection for the cadastre of real estates. However RPAS as a data collection tool for cadastral purposes is not enshrined in the Czech legislation. This issue is currently being discussed worldwide. For the European Union and its Member States, there is no uniform legislative framework. Each Member State solves this problem individually and so it is, for individuals, virtually impossible to exploit commercially RPAS within the European Union. For the current Czech legislation, there are several difficulties for commercial use of RPAS:

1) The altitude restriction of flight by Civil Aviation Authority in a built-up area to $100 \mathrm{~m}$ and for rural area to $300 \mathrm{~m}$. For built-up areas, the use of RPAS has the most sense. 
2) In built-up areas, it is necessary to obtain permission from residents for imaging and consent from owners with overflight of their lands, because of the protection of personal data.

3) In terms of data processing, there are questions about the imaging; for example, it is necessary to define the maximum permitted GSD (Ground Sampling Distance) of imaging. And whether perpendicular flights should be used for the creation of models and what overlap and sidelap should be used for imaging. It should also be noted that each image processing software has different characteristics influencing outputs accuracy (depending on the used algorithm and also setting of the software).

4) It will probably be necessary to define a minimum density of control points and their optimal configuration (pattern), which may depend on the used software for data processing. Furthermore, it is necessary to define if control points should be measured by GNSS or by terrestrial method.

5) How should break points of lands be marked? Because the traditional approach (boundary stones, fences, etc.) does not satisfy the needs of RPAS.

6) How will independent verification of break points of lands be done? Should the same method be used? It is necessary to point out the dependence of the model of the same control points, which were measured by the same method, and the model was processed with the same algorithm of the software. Or should more control points to be placed in the area and should only a part of the control points be used for the processing and the others should be served as check points? Should accuracy be compulsorily tested at check points? It is also important to note the time lag of 2.5 hours between two GNSS measurements for break points of lands. This should be the same criteria for the measuring of control points and check points. In the case of double RPAS measurement of break points of lands, how will independence measurement be achieved? Will there be a sufficient lapse of time, or will you need to use another camera for photographing, should different control points for model creation be used, or different software?

For deploying RPAS as a fully-fledged system in the cadastre of real estates a lot of issues must be resolved. The main issues for the RPAS deployment in the cadastre of real estates are the lack of legislation in this area and how it will carry out a second independent measurement of break points of lands and how to check quality of results.

\section{ACCURACY COMPARISON OF USED METHODS}

\subsection{Testing field}

RPAS accuracy testing was carried out on a field near the town of Litoměrice. On the field a testing field was created, and the testing field was marked by a total of 42 targets (see Figure 1). Two targets sizes were used, $30 \times 30 \mathrm{~cm}$ and $50 \times 50 \mathrm{~cm}$ with a checkerboard pattern. The influence of the aspect ratio (1:1 and $1: 1.5$ ) and spacing control points (side was of $200 \mathrm{~m}$ and 400 m) was studied on the checkpoints. Marked points were measured by RTK GNSS method and by terrestrial measurement.

In the Figure 1, black dots are the checkpoints. Large red dots are control points of the testing field for the aspect ratio of $1: 1$ and the lower side of the testing field of $400 \mathrm{~m}$. By adding small red dots a testing field with an aspect ratio of $1: 1$ and the lower side of the testing field of $200 \mathrm{~m}$ is achieved. Blue dots indicate aspect ratio of the testing field 1:1.5. Large blue dots indicate the lower side of the testing field of $400 \mathrm{~m}$. By adding small blue dots a test field with an aspect ratio of 1:1.5 and the lower side of the testing field of $200 \mathrm{~m}$ is achieved.

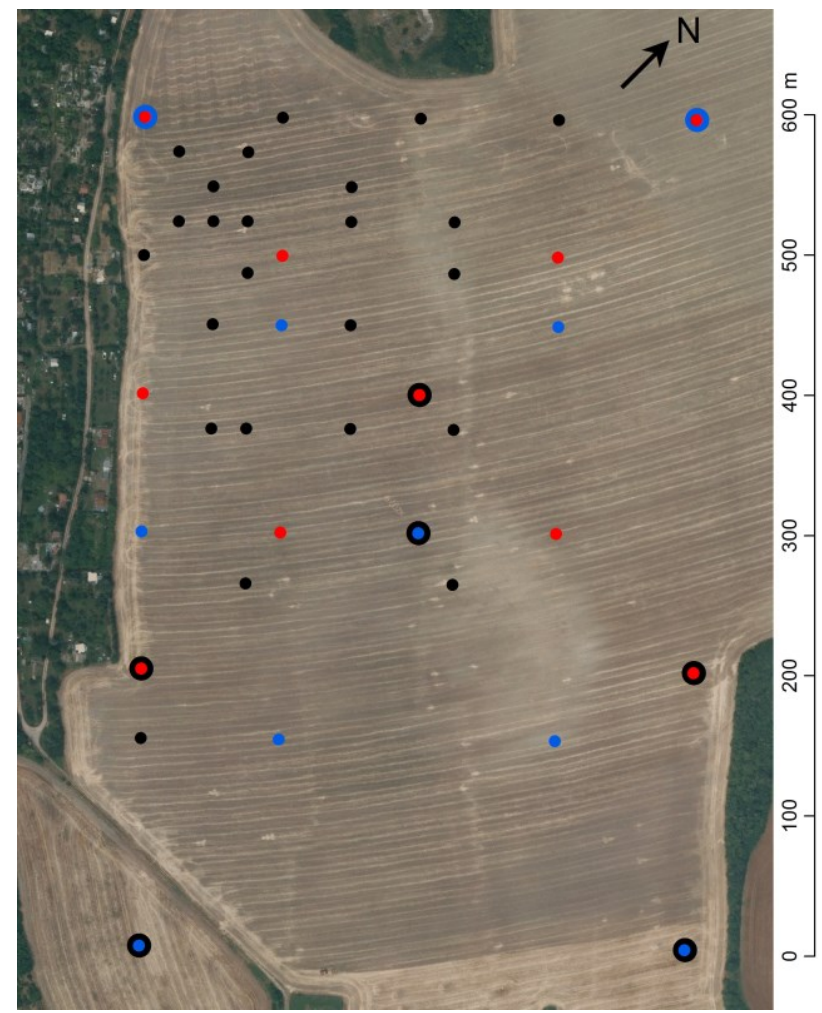

Figure 1. Testing field together with 42 marked points

\subsection{Accuracy of GNSS measurement}

For accuracy of RTK GNSS measurement a priori standard deviation value is listed in the Table 3. For measuring was used Leica VIVA GS15 was used for measuring, using the online correction of the CZEPOS net.

\begin{tabular}{|c|c|c|}
\hline $\mathrm{SD}_{X}[\mathrm{~cm}]$ & $\mathrm{SD}_{Y}[\mathrm{~cm}]$ & $\mathrm{SD}_{Z}[\mathrm{~cm}]$ \\
\hline 1.5 & 1.5 & 5.0 \\
\hline
\end{tabular}

Table 3. Accuracy of GNSS measurement of marked points

Where $\mathrm{SD}$ is standard deviation of $\mathrm{X}, \mathrm{Y}$ and $\mathrm{Z}$ coordinate.

\subsection{Accuracy of terrestrial measurement}

A traverse oriented on both ends and connected on both ends was measured between trigonometric point and net densification point. A posterior standard deviation value for terrestrial measurement is shown in the Table 4. It was calculated from the adjustment of two traverses (measured there and back). The influence of the trigonometric point and net densification point is ignored. The influence of the trigonometric point and net densification point is estimated to be about $2 \mathrm{~cm}$ in the position. The traverse was adjusted in the free software gamma-local, developed at Department of Geomatics, FCE, and CTU in Prague. All terrestrial measurements were done by total station Leica TC 307.

\begin{tabular}{|c|c|c|}
\hline SDX $[\mathrm{cm}]$ & SDy $[\mathrm{cm}]$ & $\mathrm{SD}_{Z}[\mathrm{~cm}]$ \\
\hline 0.4 & 0.4 & 0.5 \\
\hline
\end{tabular}

Table 4. Accuracy of points of adjusted traverse

Where SD is standard deviation of $\mathrm{X}, \mathrm{Y}$ and $\mathrm{Z}$ coordinate. 
The accuracy of terrestrial measurement is estimated from the double independent measurement of the marked points. Standard deviations were determined from coordinate differences. Standard deviations are shown in Table 5.

\begin{tabular}{|c|c|c|}
\hline $\mathrm{SD}_{\mathrm{X}}[\mathrm{cm}]$ & $\mathrm{SDY}[\mathrm{cm}]$ & $\mathrm{SD}_{\mathrm{Z}}[\mathrm{cm}]$ \\
\hline 1.4 & 1.8 & 0.6 \\
\hline
\end{tabular}

Table 5. Accuracy of marked points measured by terrestrial method

Where $\mathrm{SD}$ is standard deviation of $\mathrm{X}, \mathrm{Y}$ and $\mathrm{Z}$ coordinate.

\subsection{Accuracy of RPAS measurement}

For accuracy testing, the RPAS eBee (type wing) was used. RPAS was gradually equipped by a VIS (RGB) and NIR (NIRGB) camera. The testing field was imaged with different cameras in a straight and perpendicular flight lines and with several altitudes. The corresponding GSD (Ground Sampling Distance) and the number of images acquired for the flight are shown in Table 6.

\begin{tabular}{|c|c|c|c|c|}
\hline \multirow{2}{*}{$\begin{array}{c}\text { GSD } \\
{[\mathrm{cm}]}\end{array}$} & \multicolumn{2}{|c|}{ VIS } & \multicolumn{2}{c|}{ NIR } \\
\cline { 2 - 5 } & Straight & Perpendicular & Straight & Perpendicular \\
\hline 6 & 58 & 58 & 58 & 63 \\
\hline 3.5 & 139 & 115 & 151 & 142 \\
\hline 3 & 184 & - & - & 168 \\
\hline
\end{tabular}

Table 6. Flight GSD, flight line and corresponding image count

\begin{tabular}{|c|c|c|c|c|c|c|c|c|c|}
\hline \multirow{3}{*}{ 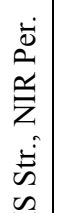 } & \multirow{3}{*}{$\frac{\bar{\Xi}}{\frac{\Xi}{N}}$} & $\stackrel{\nabla}{i}$ & $\hat{m}$ & $\stackrel{\nabla}{-}$ & $\hat{m}$ & $\tilde{n}$ & $\tilde{m}$ & 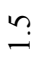 & $\dot{r}$ \\
\hline & & $\stackrel{n}{n}$ & $\underset{r}{\dot{r}}$ & $\vec{i}$ & $\stackrel{\infty}{i}$ & $\vec{i}$ & $\hat{\mathrm{d}}$ & $\stackrel{a}{\sim}$ & $\stackrel{\circ}{\circ}$ \\
\hline & & $\stackrel{\odot}{+}$ & $\ddot{g}$ & $\stackrel{\circ}{i}$ & $\stackrel{n}{n}$ & $\stackrel{\infty}{\sim}$ & $\vec{n}$ & $\stackrel{n}{\forall}$ & $\because n$ \\
\hline \multirow{3}{*}{ 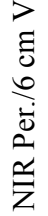 } & \multirow{3}{*}{ 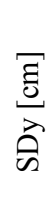 } & 9 & $\exists$ & $\because$ & $\because$ & $\stackrel{\circ}{\circ}$ & 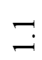 & $\stackrel{\infty}{\infty}$ & $?$ \\
\hline & & $n$ & 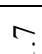 & 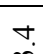 & 7 & 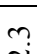 & 0 & ? & ๑. \\
\hline & & $\stackrel{r}{\forall}$ & $\stackrel{\sim}{\sim}$ & $\stackrel{a}{m}$ & $\underset{\sim}{0}$ & $\vec{m}$ & $\vec{d}$ & 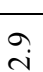 & $\stackrel{\infty}{\sim}$ \\
\hline \multirow{3}{*}{ 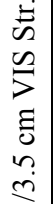 } & \multirow{3}{*}{ 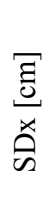 } & $\stackrel{\circ}{i}$ & $\stackrel{\circ}{i}$ & 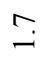 & 9 & $n$ & 9 & $\stackrel{\infty}{-}$ & $\vec{\sim}$ \\
\hline & & $\stackrel{\circ}{\ddot{m}}$ & $\stackrel{0}{i}$ & $\vec{r}$ & $\stackrel{n}{N}$ & $\hat{\mathrm{i}}$ & $\hat{\jmath}$ & $\stackrel{m}{\sim}$ & $\underset{\sim}{\sim}$ \\
\hline & & $\stackrel{n}{\sim}$ & $\vec{m}$ & $\vec{\sim}$ & $\overline{\mathrm{j}}$ & $i$ & $\stackrel{r}{m}$ & $\stackrel{m}{\sim}$ & $\underset{\sim}{\sim}$ \\
\hline \multirow{2}{*}{ 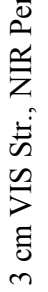 } & 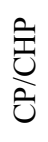 & $\begin{array}{l}n \\
\text { In } \\
\text { ¿े }\end{array}$ & 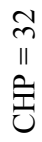 & $\begin{array}{l}n \\
\| \\
\text { Oे }\end{array}$ & $\begin{array}{l}\hat{n} \\
\| \\
\hat{\Xi} \\
\hat{\Xi}\end{array}$ & 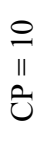 & $\begin{array}{l}\widehat{N} \\
\| \\
\tilde{\Xi} \\
\tilde{\Xi}\end{array}$ & $\begin{array}{l}\stackrel{0}{1} \\
\| \\
\text { 己े }\end{array}$ & 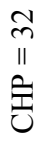 \\
\hline & 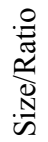 & \multicolumn{2}{|c|}{ 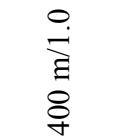 } & \multicolumn{2}{|c|}{$\begin{array}{l}n \\
\stackrel{1}{a} \\
8 \\
8\end{array}$} & \multicolumn{2}{|c|}{ 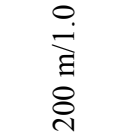 } & \multicolumn{2}{|c|}{ 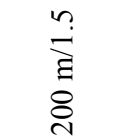 } \\
\hline
\end{tabular}

Table 7. Standard deviations of control points and check points measured by terrestrial method

Where $\mathrm{SD}$ is standard deviation of $\mathrm{X}, \mathrm{Y}$ and $\mathrm{Z}$ coordinate, $\mathrm{CP}$ is number of control points and CHP is number of checkpoints.

The accuracy of the RPAS method was tested in various combinations of GSD and in various combinations of used cameras. In Table 7 and Table 8 there are the achieved standard deviations of control points and check points for each GSD using both VIS and NIR cameras. For each GSD used, there are images from straight flight VIS camera and from perpendicular flight captured by NIR camera. In Table 7 are used coordinates of control points and check points measured by terrestrial method. And in Table 8 are measured control points and check points by GNSS measurement method. Obtained standard deviations of coordinates of control points and check points shows that the accuracy is affected by the used GSD. Against the expectation of better results are achieved with $6 \mathrm{~cm}$ GSD.

\begin{tabular}{|c|c|c|c|c|c|c|c|c|c|}
\hline \multirow{2}{*}{ 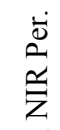 } & \multirow{3}{*}{$\frac{\tilde{D}}{\stackrel{\Xi}{0}}$} & $\stackrel{\nabla}{i}$ & ले & $\stackrel{\Xi}{-}$ & भे & $\tilde{n}$ & $m$ & $\cong$ & $\vec{m}$ \\
\hline & & $\stackrel{0}{\dot{m}}$ & $\vec{m}$ & $\vec{\sim}$ & $\overrightarrow{6}$ & $\stackrel{\sim}{\sim}$ & $\stackrel{0}{\dot{m}}$ & $\stackrel{\circ}{\stackrel{\circ}{\circ}}$ & $\stackrel{\sim}{+}$ \\
\hline \multirow{4}{*}{ 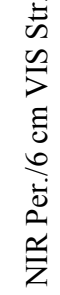 } & & $\stackrel{r}{r}$ & in & 우 & $\stackrel{\infty}{r}$ & $\dot{\rho}$ & $\vec{n}$ & $\dddot{q}$ & 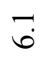 \\
\hline & \multirow{3}{*}{$\frac{\overline{0}}{\stackrel{\Xi}{0}}$} & $\stackrel{9}{-}$ & $\exists$ & $\because$ & $\cong$ & $\stackrel{0}{-}$ & 二 & $\stackrel{\infty}{-}$ & $\because$ \\
\hline & & $\vec{m}$ & $\stackrel{\nabla}{-}$ & $\hat{\sim}$ & $\exists$ & $\stackrel{\circ}{i}$ & $n$ & กี & $\stackrel{n}{\sim}$ \\
\hline & & $\stackrel{\eta}{\forall}$ & $\stackrel{\rho}{-}$ & 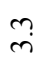 & 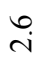 & $\stackrel{\infty}{i}$ & $\stackrel{\infty}{-}$ & $\stackrel{\sim}{\sim}$ & $\stackrel{\nabla}{\sim}$ \\
\hline \multirow{3}{*}{ 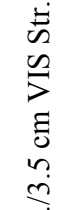 } & \multirow{3}{*}{$\frac{\vec{\Xi}}{\stackrel{\Xi}{*}}$} & $\stackrel{\leftrightarrow}{i}$ & $\stackrel{\leftrightarrow}{\mathrm{i}}$ & I & 9 & $\because$ & $\stackrel{9}{-}$ & $\stackrel{\infty}{\infty}$ & $\bar{c}$ \\
\hline & & $\hat{i}$ & $\vec{i}$ & $\stackrel{+}{\sim}$ & $\stackrel{0}{i}$ & $\vec{\sim}$ & $\stackrel{\sim}{\sim}$ & $\stackrel{\circ}{i}$ & ゙ָ \\
\hline & & $\stackrel{\sim}{\sim}$ & $\begin{array}{l}\circ \\
\text { i }\end{array}$ & 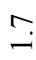 & $\ddot{n}$ & $\stackrel{9}{-}$ & $\begin{array}{l}o \\
i\end{array}$ & 9 & $\stackrel{\bullet}{i}$ \\
\hline \multirow{2}{*}{ 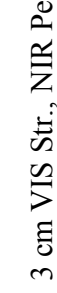 } & $\underset{ٍ}{ٍ}$ & $\begin{array}{l}n \\
\| \\
\tilde{U}\end{array}$ & $\begin{array}{l}\text { N } \\
\| \\
\stackrel{\Xi}{U}\end{array}$ & $\begin{array}{l}n \\
\| \\
\text { 己े }\end{array}$ & $\begin{array}{l}\hat{m} \\
\| \\
0 \\
\end{array}$ & $\begin{array}{l}0 \\
\text { ॥ } \\
\text { ¿ }\end{array}$ & $\begin{array}{l}\hat{N} \\
\| \\
\hat{\Xi} \\
\tilde{U}\end{array}$ & $\begin{array}{l}\stackrel{0}{\|} \\
\text { ชి }\end{array}$ & $\begin{array}{l}\text { N } \\
\| \\
\text { 全 }\end{array}$ \\
\hline & 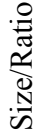 & \multicolumn{2}{|c|}{ 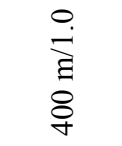 } & \multicolumn{2}{|c|}{$\begin{array}{l}n \\
\stackrel{n}{\Xi} \\
\stackrel{8}{8}\end{array}$} & \multicolumn{2}{|c|}{ 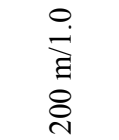 } & \multicolumn{2}{|c|}{ 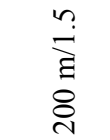 } \\
\hline
\end{tabular}

Table 8. Standard deviations of control points and check points measured by RTK GNSS method

Where $\mathrm{SD}$ is standard deviation of $\mathrm{X}, \mathrm{Y}$ and $\mathrm{Z}$ coordinate, $\mathrm{CP}$ is number of control points and CHP is number of checkpoints.

Table 9 shows the quadratic mean of standard deviation of control points together with checkpoints. Models were created by combining VIS and NIR images. First images were VIS straight and NIR perpendicular and then changed for VIS perpendicular and NIR straight. GSD combination were $3 \mathrm{~cm}$ with $3.5 \mathrm{~cm}, 3 \mathrm{~cm}$ with $6 \mathrm{~cm}$ and $3.5 \mathrm{~cm}$ with $6 \mathrm{~cm}$, for this combinations were computed quadratic mean standard deviations together and are marked as Mix.

\begin{tabular}{|c|c|c|c|c|}
\hline Measurement & GSD & SDx $[\mathrm{cm}]$ & SDy $[\mathrm{cm}]$ & SDz $[\mathrm{cm}]$ \\
\hline \multirow{4}{*}{ Terrestrial } & 3 & 2.7 & 3.2 & 5.3 \\
\cline { 2 - 5 } & 3.5 & 2.7 & 2.5 & 3.6 \\
\cline { 2 - 5 } & 6 & 1.9 & 1.5 & 3.0 \\
\cline { 2 - 5 } & Mix & 2.4 & 2.3 & 4.3 \\
\hline \multirow{4}{*}{ GNSS } & 3 & 2.3 & 2.8 & 5.5 \\
\cline { 2 - 5 } & 3.5 & 2.2 & 2.1 & 3.7 \\
\cline { 2 - 5 } & 6 & 1.9 & 1.5 & 3.0 \\
\cline { 2 - 5 } & Mix & 2.0 & 2.0 & 4.1 \\
\hline
\end{tabular}

Table 9. Achieved standard deviations of control points and check points measured by RTK GNSS and terrestrial method 
Where SD is standard deviation of $\mathrm{X}, \mathrm{Y}$ and $\mathrm{Z}$ coordinate, GSD is Ground Sampling Distance.

In Table 10 are estimated standard deviations of coordinates for RPAS method. Accuracy of method RPAS meets with the required accuracy of the cadastre of real estates of the Czech Republic.

\begin{tabular}{|c|c|c|}
\hline $\mathrm{SD}_{\mathrm{X}}[\mathrm{cm}]$ & $\mathrm{SD}_{\mathrm{Y}}[\mathrm{cm}]$ & $\mathrm{SD}_{Z}[\mathrm{~cm}]$ \\
\hline $2.0-3.0$ & $2.0-3.0$ & $4.0-5.0$ \\
\hline
\end{tabular}

Table 10. Estimated standard deviations of coordinates for RPAS method

Where SD is standard deviation of $\mathrm{X}, \mathrm{Y}$ and $\mathrm{Z}$ coordinate.

\section{COMPARISON OF METHODS}

\subsection{Comparison of GNSS and terrestrial method}

Table 11 compares $\mathrm{X}, \mathrm{Y}$ and $\mathrm{Z}$ coordinate differences. We calculated the average shift for each coordinate. Table 11 includes inaccuracy both of GNSS and terrestrial measurements of all 42 marked points. Testing field was about $5 \mathrm{~km}$ far from a CZEPOS permanent station of the CZEPOS net, which was used for RTK GNSS measurement.

\begin{tabular}{|c|c|c|c|}
\hline & SDX $_{X}[\mathrm{~cm}]$ & SDY $[\mathrm{cm}]$ & $\mathrm{SD}_{Z}[\mathrm{~cm}]$ \\
\hline Shift & 1.3 & 4.2 & 1.6 \\
\hline SD & 1.1 & 1.1 & 0.8 \\
\hline
\end{tabular}

Table 11. Estimated shift and standard deviations between RTK GNSS and terrestrial method

\subsection{Comparison of GNSS and RPAS method}

Table 12 summarizes the achieved standard deviations at checkpoints between RPAS and GNSS measurements for the lower side of the testing field of $400 \mathrm{~m}$ and an aspect ratio of 1:1. No significant influences of side lengths $400 \mathrm{~m}$ and $200 \mathrm{~m}$ and an aspect ratio of $1: 1$ and 1:1.5 were found out. In $61 \%$ it was achieved a better standard deviation on check points, for the aspect ratio $1: 1$. However, only $30 \%$ of the differences were greater than $0.5 \mathrm{~cm}$. In $58 \%$, better results was achieved for the lower side of the testing field of $200 \mathrm{~m}$, but only for $26 \%$ were achieved better results than $0.5 \mathrm{~cm}$.

\begin{tabular}{|c|c|c|c|c|c|c|c|c|c|}
\hline CHP & SDx [cm] & SDy [cm] & \multicolumn{2}{c|}{ SDz [cm] } \\
\hline \multicolumn{7}{|c|}{3 cm VIS Str., NIR Per. / 3.5 cm VIS Str., NIR Per. / } \\
6 cm VIS Str., NIR Per. \\
\hline 32 & 2.6 & 2.1 & 2.0 & 1.9 & 1.4 & 1.1 & 5.9 & 3.7 & 3.9 \\
\hline VIS 3.5 cm Str., NIR 3 cm Per. / VIS 3 cm Str., NIR $3.5 \mathrm{~cm}$ \\
Per. \\
\hline 32 & 2.1 & 2.9 & 1.4 & 2.0 & 5.3 & 5.3 \\
\hline \multicolumn{7}{|c|}{ VIS 6 cm Str., NIR 3 cm Per. / } \\
\hline 32 & 1.9 & 2.4 & 1.3 & 1.4 & 3.1 & 5.8 \\
\hline \multicolumn{7}{|c|}{ VIS 6 cm Str., NIR $3.5 \mathrm{~cm}$ Per. / } \\
\hline 31 & 1.4 & 1.8 & 1.6 & 1.3 & 5.9 & 4.3 \\
\hline VIS 3.5 cm Str., NIR 6 cm Per. \\
\hline 32 & 2.4 & 1.3 & 1.4 & 1.0 & 3.0 & 3.1 \\
\hline
\end{tabular}

Table 12. Estimated standard deviations between RTK GNSS and RPAS method
Where $\mathrm{SD}$ is the standard deviation of $\mathrm{X}, \mathrm{Y}$ and $\mathrm{Z}$ coordinates, CHP is number of check po

\subsection{Comparison of terrestrial and RPAS method}

In Table 13 the standard deviations of coordinates at check points between RPAS and terrestrial measurements are shown, for the lower side of the testing field of $400 \mathrm{~m}$ and an aspect ratio of $1: 1$. For an aspect ratio of $1: 1$ better results were achieved in $71 \%$, but in only $29 \%$ is the difference greater than $0.5 \mathrm{~cm}$. In $65 \%$, better results were achieved for the lower side of the testing field of $200 \mathrm{~m}$, but only in $25 \%$ is the difference greater than $0.5 \mathrm{~cm}$.

\begin{tabular}{|c|c|c|c|c|c|c|c|c|c|}
\hline CHP & SDx [cm] & SDy [cm] & \multicolumn{2}{c|}{ SDz [cm] } \\
\hline \multicolumn{7}{|c|}{$6 \mathrm{~cm}$ VIS Str., NIR Per. / $3.5 \mathrm{~cm}$ VIS Str., NIR Per. / } \\
\hline 32 & 3.1 & 2.6 & 2.0 & 2.2 & 1.7 & 1.1 & 5.9 & 3.4 & 3.9 \\
\hline VIS 3.5 cm Str., NIR 3 cm Per. / VIS 3 cm Str., NIR $3.5 \mathrm{~cm}$ \\
Per. \\
\hline 32 & 2.8 & 3.3 & 1.6 & 2.4 & 5.0 & 5.3 \\
\hline \multicolumn{7}{|c|}{ VIS $6 \mathrm{~cm}$ Str., NIR 3 cm Per. / } \\
\hline 32 & 2.4 & 2.8 & 1.6 & 1.8 & 3.1 & 5.9 \\
\hline \multicolumn{7}{|c|}{ VIS $6 \mathrm{~cm}$ Str., NIR $3.5 \mathrm{~cm}$ Per. / } \\
\hline VIS $3.5 \mathrm{~cm}$ Str., NIR $6 \mathrm{~cm}$ Per. \\
\hline 31 & 1.4 & 2.4 & 1.4 & 1.3 & 6.2 & 4.1 \\
\hline \multicolumn{7}{|c|}{ VIS $3 \mathrm{~cm}$ and $6 \mathrm{~cm}$ Str., NIR $3.5 \mathrm{~cm}$ Per. / All images } \\
\hline 32 & 3.0 & 2.0 & 1.8 & 1.3 & 2.9 & 3.2 \\
\hline
\end{tabular}

Table 13. Estimated standard deviations between terrestrial and RPAS method

Where SD is the standard deviation of $\mathrm{X}, \mathrm{Y}$ and $\mathrm{Z}$ coordinates, CHP is number of checkpoints.

\section{CONCLUSIONS}

In the cadastre of real estates of the Czech Republic, aerial photogrammetry was used and is still the authorized method for the renewal of cadastre documentation. This method is very expensive and for its use it is necessary to have a larger area than one cadastral unit. RPAS is a suitable alternative for the mapping of smaller areas; however, it suffers the classic problems of aerial photogrammetry when mapping e.g. it is necessary to remove the roof overlapping. RPAS as a mapping instrument and as a mapping technology is not enshrined in the Czech legislation. The RPAS process of integration into legislation is still underway. The Accuracy of RPAS technology is comparable to the terrestrial and GNSS measurements, as is evidenced above. When testing RPAS accuracy, significant differences in the aspect ratio of $1: 1$ and $1: 1.5$ and the lower side of the testing field of $200 \mathrm{~m}$ and $400 \mathrm{~m}$ haven't been demonstrated. It is probably a matter of time when RPAS as a mapping instrument for the cadastral of real estates will be accepted at the Czech Republic and at the entire world.

\section{ACKNOWLEDGEMENTS}

This work was supported by the Grant Agency of the Czech Technical University in Prague, under grant no. SGS16/063/OHK1/1T/11 - Innovative Approaches in the Field of Geomatics: Data Collection, Processing and Analyses. 


\section{REFERENCES}

Barešová, E., Bláhová, I., Doubek, P., Janeček, B., Nedvídek, L., Šandová, H., 2015. Katastrální zákon: komentár. Wol ters Kluwer, a.s., Praha.

Cramer, M., Haala, N., Rothermel, M., Leinss, B., Einss a Fritsch, D., 2013. Photogrammetrie - Fernerkundung Geoinformation "UAV@LGL - Pilotstudie zum Einsatz von UAV im Rahmen der Landesvermessung in Deutschland", Stuttgart, Germany https://www.schweizerbart.de/papers/pfg/detail/2013/80890/UA VLGL_Pilotstudie_zum_Einsatz_von_UAV_im_Rahmen_der_ Landesvermessung_in_Deutschland (18 Dec. 2015$)$.

ČÚZK, 2013. Návody ČÚZK "NÁVOD PRO OBNOVU KATASTRÁLNÍHO OPERÁTU A PŘEVOD”, Prague, Czech Republic http://www.cuzk.cz/Predpisy/Resortni-predpisy-aopatreni/Navody-CUZK/Navod_150150022.aspx (11 Dec. 2015).

Housarová, E., Pavelka, K., Šedina, J., 2015. Testing rpas for cadastre purposes, International Multidisciplinary Scientific GeoConference Surveying Geology and Mining Ecology Management, SGEM 2015, pp. 1135-1142.

Manyoky, M., Theiler, P., Steudler, D., Eisenbeiss, H., 2011. Unmanned aerial vehicle in cadastral applications, International Archives of the Photogrammetry, Remote Sensing and Spatial Information Sciences - ISPRS Archives 2011, pp. 57-62.

Šedina, J., Pavelka, K., Housarová, E., 2016. Rpas as a tool for mapping and other special work, Advances and Trends in Engineering Sciences and Technologies - Proceedings of the International Conference on Engineering Sciences and Technologies, ESaT 2015 2016, pp. 405-411. 